\title{
A Case Report of Cardiac Arrest during General Anesthesia
}

\section{Nahid Manouchehrian", Masoud Tarbiat²,*}

${ }^{1}$ Associate Professor, Department of Anesthesiology, School of Medicine, Hamadan University of Medical Sciences, Hamadan, Iran

${ }^{2}$ Assistant Professor, Department of Anesthesiology, School of Medicine, Hamadan University of Medical Sciences, Hamadan, Iran

* Corresponding Author: Masoud Tarbiat, Department of Anesthesiology, School of Medicine, Hamadan University of Medical Sciences, Hamadan, Iran.Email: masoudtarbiat@gmail.com

\section{Abstract}

Received: 15.01 .2018

Accepted: 16.04 .2018

\section{How to Cite this Article:}

Manouchehrian N, Tarbiat M. A

Case Report of Cardiac Arrest during General Anesthesia. Avicenna J Clin Med. 2018; 25(1): 63-66. DOI: 10.21859/ajcm. 25.1.63.
Background: Cardiac arrest during general anesthesia is a rare and potentially fatal condition. Despite the progression of monitoring equipments and anesthetic mediations, this phenomenon is still an important problem for the anesthesiologists.

Case Presentation: Herein, we reported a 38-year-old opium addict plasterer male scheduled for laminectomy. He had no previous medical history and took no regular medication. Anesthesia was slowly induced with the intravenous administration of midazolam $2 \mathrm{mg}$, sufentanil $10 \mu \mathrm{g}$, sodium thiopental $300 \mathrm{mg}$, and atracurium $30 \mathrm{mg}$. The patient suddenly experienced respiratory distress, severe bradycardia, and cardiac arrest. Therefore, he was immediately subjected to cardiopulmonary resuscitation and intubation. Finally, the patient became hemodynamically stable and fully conscious and alert. He was extubated in operating room and transferred to the Coronary Care Unit. All laboratory tests were normal after cardiac arrest. Therefore, he was discharged in a good general condition. With regard to patient's addiction and administration of atracorum and sodium thiopental, allergic reactions (anaphylaxis) seem to be the most likely cause of cardiac arrest during anesthesia.

Conclusion: This report emphasizes that anesthetists must always make sure of continuous monitoring and availability of resuscitation equipment and drugs. Moreover, they should be prepared to appropriately diagnose and manage sudden cardiac arrest during anesthesia.

Keywords: Anaphylaxis, Cardiac Arrest, General Anesthesia 
كزارش يك مورد ايست قلبى در حين بيهوشى عمومى

\section{ناهيد منو جهريان'، مسعود تربيت ז:*}

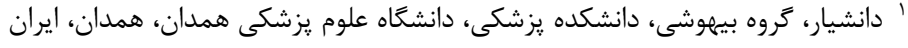

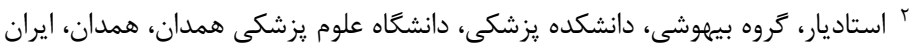

* نويسنده مسئول: مسعود تربيت، كروه بيهوشى، دانشكده يزشكى، دانشعاه علوم يزشكى همدان، همدان، ايران. ايميل: masoudtarbiat@gmail.com

\begin{tabular}{|c|c|}
\hline جكيده & \\
\hline 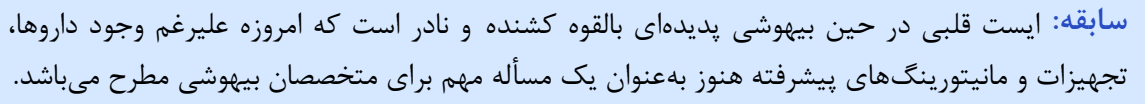 & 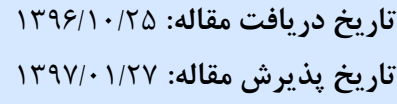 \\
\hline معرفى بيمار: بيمار مردى ^^ ساله، كَّار و معتاد به مواد مخدر بود كه براى انجام جراحى لامينكتومى & \\
\hline بسترى شده بود. در شرح حال بيمار سابقه هيجَّونه بيمارى و مصرف دارو ثبت نتشته بود. اينداكشن بيهوشى & لتمامى حقوق نشر براى دانشكاه علوم \\
\hline 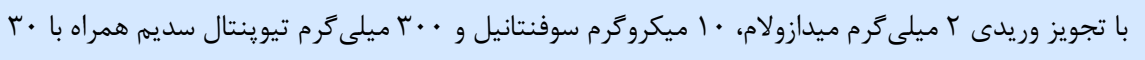 & \\
\hline ميلى كرم آتراكوريوم بهصورت آهسته انجام شد. بِ از اينداكشن، بيمار بهطور ناكهانى دجار تنغى نفس، & \\
\hline براديكاردى شديد و ايست قلبى گرديد. در ادامه، بلافاصله عمليات احياى قلبى- ريوى آغاز گشت و بيمار & \\
\hline اينتوبه شد. سرانجام، بيمار ثبات هموديناميك يافت و بهطور كامل بيدار و هوشيار كرديد. لوله تراشه بيمار در & \\
\hline اتاق عمل خارج كشت و بيمار به CCU منتقل شد. شايان ذكر است كه تمام آزمايشات بيمار پِ از ايست & \\
\hline قلبى نرمال بود؛ از اين رو با حال عمومى خوب مرخص شد. با توجه به اعتياد و تجويز داروهاى آتراكوريم و & \\
\hline تيوينتال سديم به نظر مىرسد كه محتملترين علت ايست قلبى در حين بيهوشى ناشى از واكنشهاى آلرزيك & \\
\hline 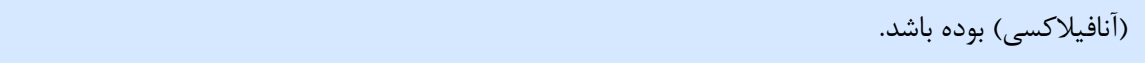 & \\
\hline نتيجه كيرى: كزارش حاضر بر اين نكته تأكيد دارد كه هميشه متخصصان بيهوشى بايد از مانيتورينَ مداوم & \\
\hline بيمار و دردسترسبودن داروها و تجهيزات احياى قلبى- ريوى اطمينان حاصل نموده و آمادكى لازم براى & \\
\hline تشخيص و برخورد مناسب با ايست قلبى ناكهانى حين بيهوشى را داشته باشند. & \\
\hline وازًان كليدى: آنافيلاكسى، ايست قلبى، بيهوشى عمومى & \\
\hline
\end{tabular}

$$
\text { ايست قلبى در حين بيهوشى عمومى را شرح مىدهيم. }
$$

\section{معرفى بيمار}

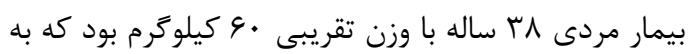

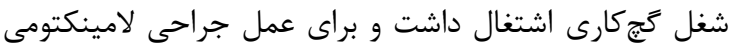

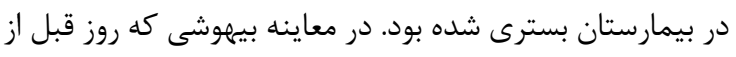

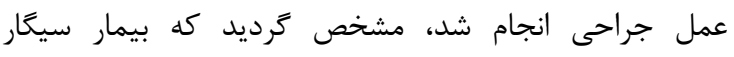

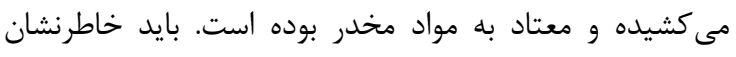

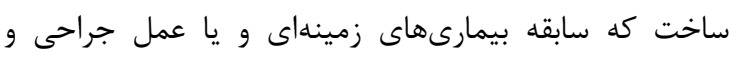

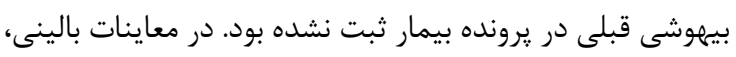

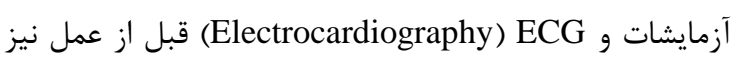

نكته خاصى مشاهده نشد. يس از ورود به اتاق عمل براى بيمار دو لاين وريدى مناسب
مقلدمه

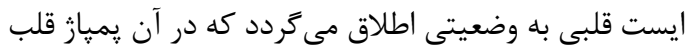

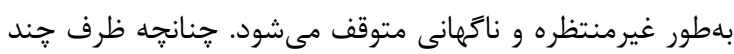
دقيقه اول يس از ايست قلبى اقدامات مناسب انجام نشود، ممكن

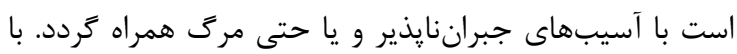

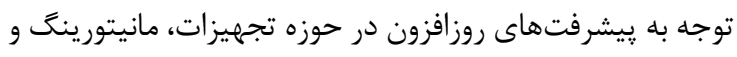

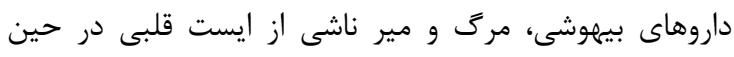

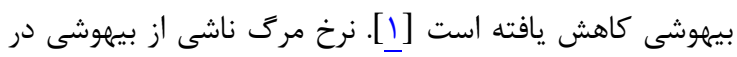

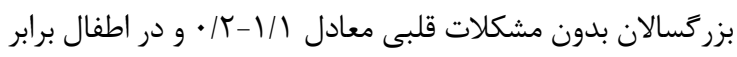

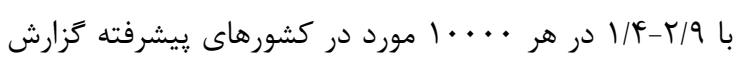

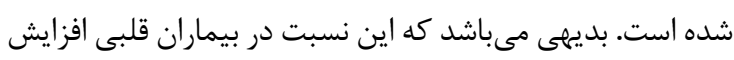

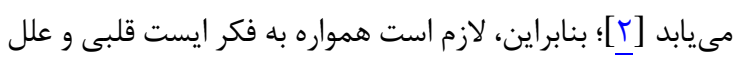

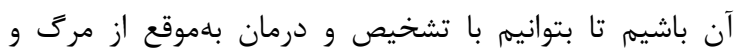

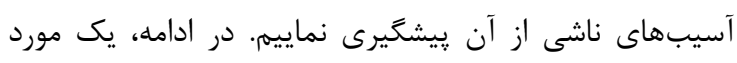


نكرديد. با اين وجود، بيمار به مدت دو روز در بخش CCU تحت نظر بود و با حال عمومى مناسب مرخص شد.

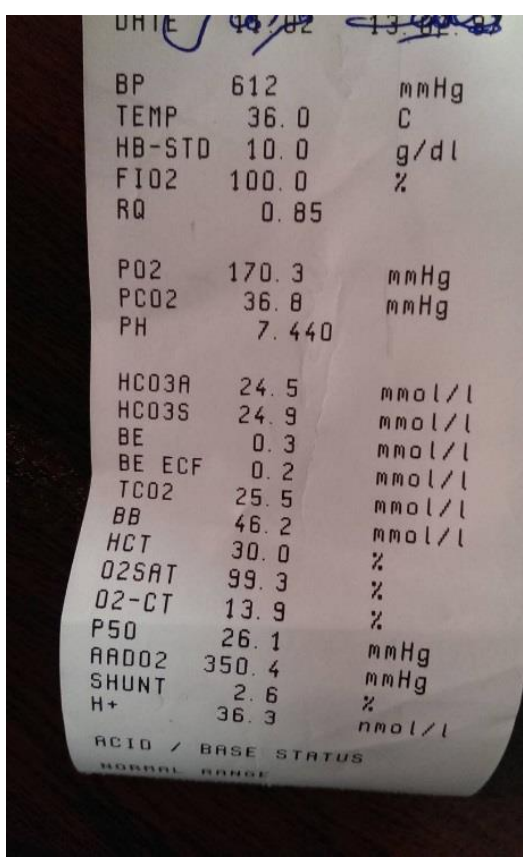

شكل ا: ABG بيمار مورد مطالعه

بحث

ايست قلبى در حين بيهوشى بسيار نادر است. براساس

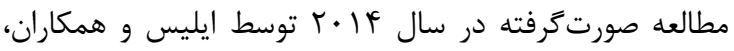

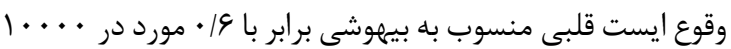

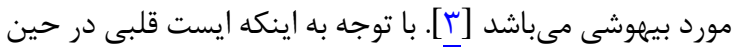

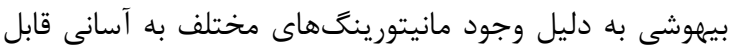

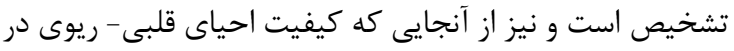

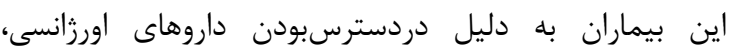

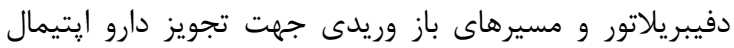

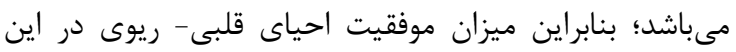

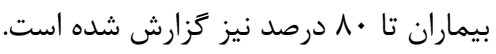
از نظر اتيولوزى، علل ايست قلبى در حين بيهوشى به ينج

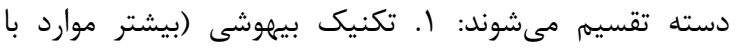

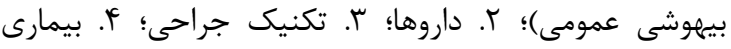

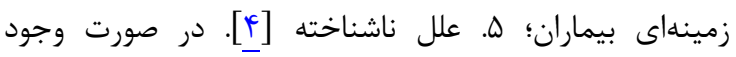
بيمارىهاى زمينهاى در بيمار ممكن است ايست قلبى طى لى لى

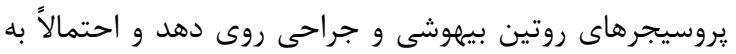

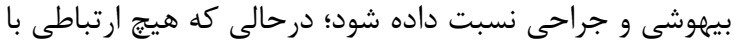

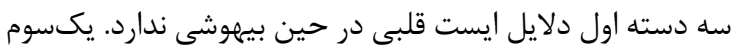
از ايستهاى قلبى در حين بيهوشى در زمان اينداكشن (شروع)

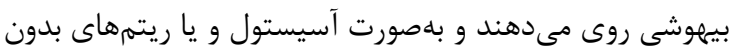

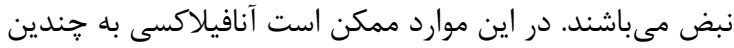
داروى بيهوشى از جمله داروهاى شل كننده عضلانى (ساكسنيل كولين، آتراكوريوم و روكورونيوم)، هوشبرهاى ورئ وريدى (تيوينتال
برقرار كشت و حدود •Uأ ميلىليتر سرم رينكر انفوزيون گَرديد

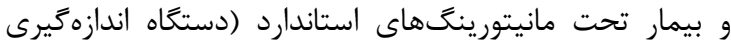
فشار خون، ضربان قلب، ECG و پالس اكسيمترى) قرار گرفت. شايان ذكر است كه قبل از شروع اينداكشن بيهوشى، فشار خون

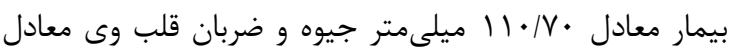
F أو در دقيقه بود.

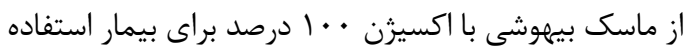

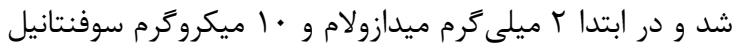

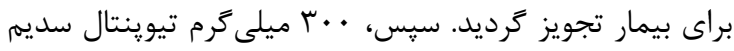

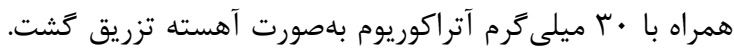

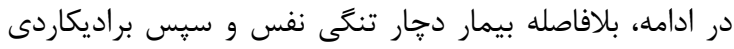

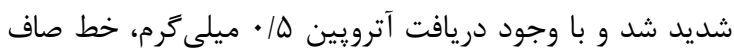

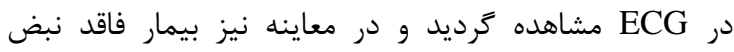

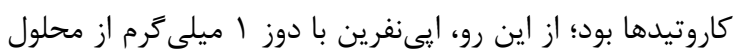

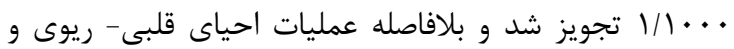

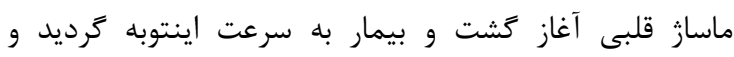

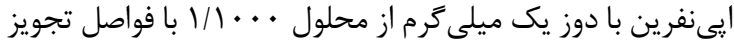
شد. يس از كذشت جند بند دقيقه از عمليات احيا، ريتم بيمار

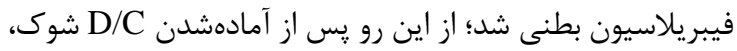

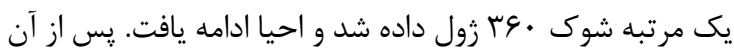

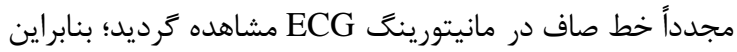
ماساز قلبى و تجويز ايى نفرين ادامه پِيدا كرد و ريتم قلبى بيمار

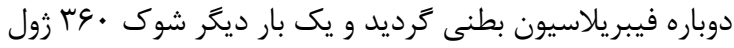

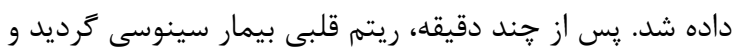

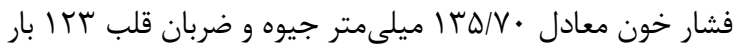
در دقيقه ثبت گرديد. در ادامه، هيدروكورتيزون • ․

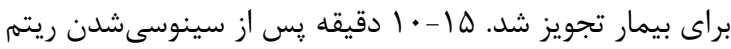

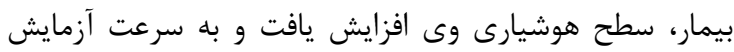

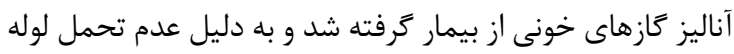

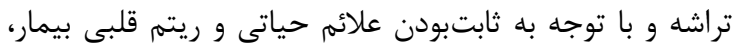

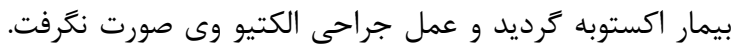

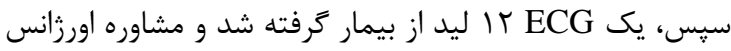

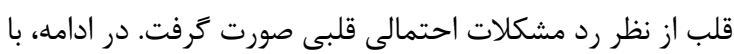

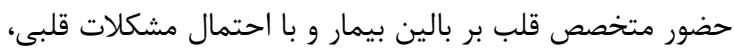

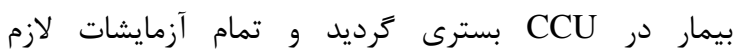
(الكتروليتها، هموكلوبين، قند خون و ترويونين سرم) براى بيمار

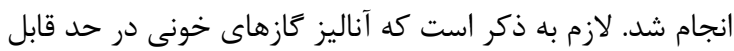
قبولى بود.

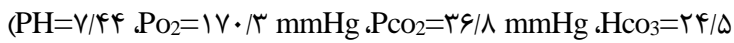
mmol/l ، Sao2=99/r) (شكل ().

در ECG كه بلافاصله يس از سينوسىشدن ريتم قلب گرفته

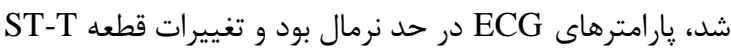

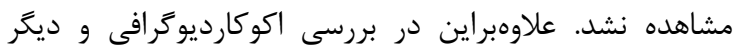

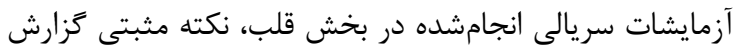


IgE مىتوان از آزمونهاى يوستى و اندازهكيرى ترييتاز و اختصاصى استفاده نمود كه البته تنهيا (Immunoglobulin E)

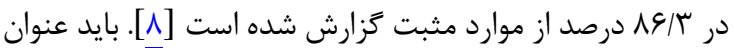
نمود كه در ارتباط با بيمار فوق به دليل عدم همكارى ودى وى اين

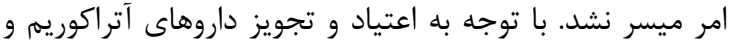

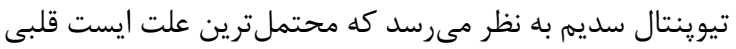

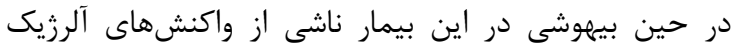

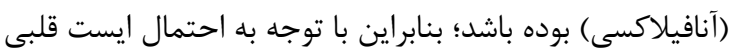

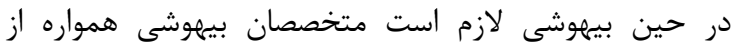
مانيتورينغ مداوم و دردسترسبودن داروها و و تجهيزات احياى

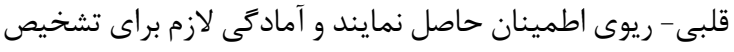

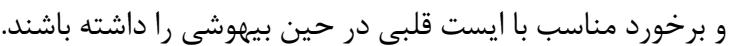

\section{REFERENCES}

1. Zuercher M, Ummenhofer W. Cardiac arrest during anesthesia. Curr Opin Crit Care. 2008,14(3):269-74. PMID: 18467885 DOI: $10.1097 / \mathrm{MCC} .0 \mathrm{~b} 013 \mathrm{e} 3282 \mathrm{f} 948 \mathrm{~cd}$

2. Fick RP, Sprung J, Harrison TE, Gleich SJ, Schroeder DR, Hanson AC, et al. Perioperative cardiac arrests in children between 1988 and 2005 at a tertiary referral center: a study of 92881 patients. Anesthesiology. 2007;106(2):226-37. PMID: 17264715

3. Ellis SJ, Newland MC, Simonson JA, Peters KR, Romberger DJ, Mercer DW, et al. Anesthesia-related cardiac arrest. Anesthesiology. 2014,120(4): 829-38. PMID: 24496124 DOI: 10.1097/ALN. 0000000000000153

4. Runciman WB, Morris RW, Watterson LM, Williamson JA, Paix AD. Crisis management during anesthesia: cardiac arrest. Qual Saf Health Care. 2005;14(3):e14. PMID: 15933287 DOI: $10.1136 /$ qshc. 2002.004473
سديم و يرويوفول) و يا مخدرها (مورفين و يِيتيدين) مطرح باشد

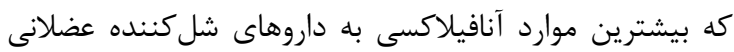

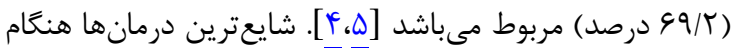

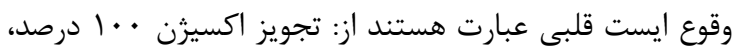

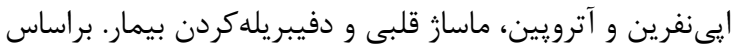

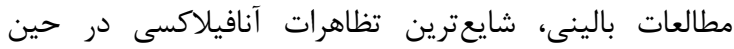

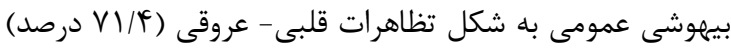

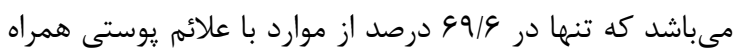

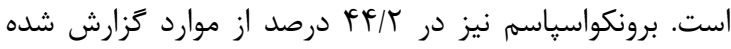

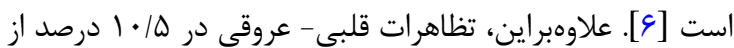

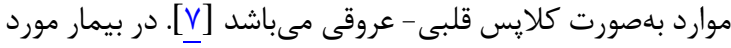

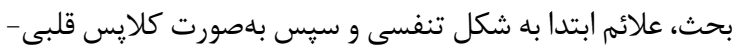

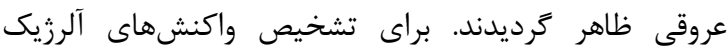

5. Miller RD, Cohan NH, Eriksson LI, Fleisher LA, Kronish JP, Young WL. Miller's anesthesia. $8^{\text {th }}$ ed. Canada: Elsevier Saunders; 2015.

6. Mertes PM, Laxenaire MC, Alla F. Anaphylactic and anaphylactoid reactions occurring during anesthesia in France in 1997-2002. Anesthesiology. 2003;99(3): 536-45.

7. Dewachter P, Mouton-Faivre C. What investigation after in anaphylactic reaction during anesthesia? Curr Opin Anesthesiol. 2008;21(3):363-8. PMID: 18458556 DOI: 10.1097/ACO.0b013e3282ff85e1

8. Mertes PM, Malinovsky JM, Jouffroy L; Working Group of the SFAR and SFA, Aberer W, Terreehorst I, et al. Reducing the risk of anaphylaxis during anesthesia: 2011 updated guidelines for clinical practice. J Investiq Allergol Clin Immunol. 2011;21(6):442-53. PMID: 21995177 